\title{
CHARRÚAS, BOHANES, PAMPAS Y GUENOA MINUANOS EN LOS PUEBLOS DE MISIONES
}

\author{
Charrúas, Bohanes, Pampas and Guenoa Minuanos in the villages/towns of Missions
}

\section{Diego Bracco*}

\section{Resumen}

En el marco de las investigaciones que se llevan a cabo en el Polo de Desarrollo Universitario: "Centro de investigaciones interdisciplinarias sobre la presencia indígena misionera en el territorio: patrimonio, región y frontera culturales" (Centro Universitario de Tacuarembó; Universidad de la República) se está prestando atención relevante a la presencia de charrúas, bohanes, pampas y guenoa minuanos en los pueblos de misiones. La investigación contribuye a resaltar que la expresión "guaraní misionero" -tradicionalmente empleada como sinónimo de "indígena misionero"- es inadecuada porque deja de lado esa presencia.

Muchos de los indígenas que eran preponderantes en las llanuras situadas al sur de las reducciones se incorporaron a los pueblos de misiones por voluntad o por fuerza. En algunos casos permanecieron allí durante generaciones, manteniendo aspectos relevantes de su identidad. El objetivo de esta contribución es poner de manifiesto esas circunstancias, especialmente en lo referido a San Borja y Yapeyú. Asimismo, destacar la influencia de la complejidad antes señalada en el espacio de frontera sobre el que se edificó la República Oriental del Uruguay.

$$
<\text { Charrúas }><\text { Guenoa }><\text { Minuanos }><\text { Bohanes }><\text { Misioneros }><\text { Fronteras }>
$$

\begin{abstract}
Within the framework of research carried out at the University Development Pole "Centro de investigaciones interdisciplinarias sobre la presencia indígena misionera en el territorio: patrimonio, región y frontera culturales" (Centro Universitario de Tacuarembó; Universidad de la República), relevant attention is being paid to the presence of charruas, bohanes, pampas and guenoa minuanos in mission towns. The research contributes to emphasize that the expression "missionary guarani" - traditionally used as a synonym for "missionary indigenous" - is inadequate, since it ignores the fact of their presence.

Many of the natives who were predominant in the plains south of the reductions joined the villages of missions by acceptance or by force. In some cases, they remained there for generations, maintaining relevant aspects of their identity. The aim of this contribution is to highlight these circumstances, especially with regard to San Borja and Yapeyú. Moreover, I will emphasize the influence of the complexity previously indicated in the borderlands on which the Oriental Republic of Uruguay was built.
\end{abstract}

$$
<\text { Charruas }><\text { Guenoa }><\text { Minuanos }><\text { Bohanes }><\text { Missionaries }><\text { Borders }>
$$

Aceptado: 25/09/2016 // Aprobado: 10/12/2016

* Centro de investigaciones interdisciplinarias sobre la presencia indígena misionera en el territorio. Centro Universitario de Tacuarembó. Universidad de la República (Uruguay) Doctor en Historia. UdelaR (Uruguay).dbracco@hotmail.com 


\section{Introducción}

Tras la llegada de los europeos se generó un espacio de fronteras en el Río de la Plata. Desde ese espacio los indígenas interactuaron con la avanzada colonial española situada al oeste, con la sociedad jesuítico misionera establecida al norte y hacia el este con las avanzadas portuguesas. Desde que la documentación referida al interior del espacio referido se tornó abundante, señaló la preponderancia de dos grandes naciones ${ }^{1}$ indígenas: charrúas y guenoa minuanos. ${ }^{2}$ Los charrúas tendieron a dominar el territorio situado entre los ríos Paraná y Uruguay hasta que una operación militar del año 1750 les asestó un duro golpe. Generalmente los bohanes, que a veces parecen parte de esa nación y en ocasiones una entidad independiente, tendieron a mantener buenas relaciones con ellos. Entretanto aquellos indígenas que los jesuitas llamaron guenoas mientras españoles y portugueses los denominaban minuanes señorearon el territorio sobre el que hoy se asienta la República Oriental del Uruguay y parte del estado de Río Grande do Sul (López y Bracco, 2010). Las dos naciones nombradas tendieron a la enemistad recíproca y, con altibajos, mantuvieron alianzas diferenciadas. Charrúas y santafesinos tendieron a cooperar en torno a intereses comunes; entretanto en general las relaciones entre guenoa - minuanos y la sociedad jesuítico misionero fueron buenas.

Además, sin perjuicio de las nombradas y otras naciones como la chaná, hubo indígenas generalmente denominados "pampas" que llegaron "desnaturalizados" al espacio de frontera. Desde allí, en ocasiones esos indígenas volvieron a ser deportados con destino a los pueblos de misiones.

\section{Charrúas $^{3}$}

Desde muy temprano hubo interacción entre los indígenas misioneros, especialmente los establecidos en Yapeyú, y los charrúas. Esa interacción parece haber tendido inicialmente a la mutua conveniencia. Quizás ello se debió a que, según diversos indicios, había proximidad y parentesco entre los indígenas establecidos en ese pueblo y los charrúas. Por ejemplo, a la muerte en Yapeyú de un joven a raíz de un accidente de caza

\section{"hizo toda la parentela notables extremos de sentimiento, y llenaron el pueblo de alaridos, y la madre que era charrúa,}

\footnotetext{
'El término "nación" es empleado en este texto siguiendo a las fuentes, que lo usaron con diversos significados pero en general reconociendo la existencia de dos grandes naciones "infieles" en el espacio de fronteras objeto de esta contribución.

2 Gran cantidad de documentación demuestra que, sin perjuicio de diferentes maneras de escribir esos nombres, la nación que los jesuitas llamaron guenoa fue denominada minuana por españoles y portugueses. Abundantes fuentes al respecto han sido publicadas en López y Bracco 2010. En esta contribución se insiste en emplear esos nombres conjuntamente ya que considerarlos como denominación de entidades diferentes ha oscurecido aspectos relevantes del pasado regional.

3 A efectos de esta contribución los yaros son considerados parte de la nación charrúa. Según el padre Sepp el término significaba "infiel". Carta del padre Sepp, sin fecha. En Cartas edificantes y curiosas 1753, T. VII. 1753. También los bohanes, sin perjuicio de que se trata de una discusión académica vigente, son considerados parte de esa nación.
} 
con todas sus parientas se arrancaron los cabellos, y cortaron los dedos conforme al uso de su nación, que en muriendo algún deudo, todos los parientes se cortan un artejo. Quiso enterrarle el Padre como cristiano, mas no fue posible, sino que le hubieron de enterrar conforme a sus ritos porque su padre amenazaba se había de echar el Río abajo si se lo estorbaban". ${ }^{4}$

En la primera mitad del siglo XVII se afirmaba que cerca de los indígenas reducidos en Yapeyú vivían "los indios charrúas, sus parientes, con los cuales comercian. Por lo demás es esta gente de un corazón extremadamente duro y hostil al nombre cristiano". 5 El vínculo era de la suficiente intensidad como para que en la década de 1630 se señalara que había llegado a la más austral de las reducciones "un grupo de charrúas, en víspera de la fiesta de San Ignacio, a comerciar, como de costumbre". 6 Aunque nunca abandonada del todo la esperanza de que esos indígenas se avinieran a la vida en reducción decreció. Conviene recordar al respecto lo sucedido con la efímera reducción de San Andrés:

"De estos Barbaros tenian ya los fervorosos Padres Jesuitas formada nueva reducion, debaxo de la tutela de San Andres Apostol, pocas leguas mas abaxo de el Yapeyú, en las mismas tierras de los Yarós. Eran ya muchos los Christianos, y mas los Cathecumenos, que vivian con demostraciones de grande consuelo, por las comodidades, que alli gozaban, muy distintas de las que podian en su gentilicia dispension adquirir. Avian celebrado las Visperas de una gran festividad, con grande regozijo, hasta muy entrada la noche. Y la mañana siguiente, mal aconsejados de algun Ministro de el Demonio, los principales acudieron al Padre Francisco Ricardo, su Parroco (Flamenco, y un Apostol de aquella florida Christiandad, que siendo Superior de todos los Missioneros, murió el año de mil seiscientos y setenta y dos, con meritos y fama de insigne santidad.) Era este gran Missionero el que los avia reducido, á costa de inmensos trabajos, y prudentes medios. Dixeronle, que todos querian dexar el Pueblo, y bolverse a su barbaro modo. Preguntoles el Padre; qué si les faltava algo, si tenian algun pesar; si deseavan comodidad, que pudiesse darles?. Y respondiendo ellos, que tenian alli todo quanto podian apetecer;

4 Carta anua correspondiente a 1626 - 1627, del padre Nicolás Mastrillo Durán. 12 de noviembre de 1628. En: Documentos para la Historia Argentina. 1929. T. XX, p. 370.

5 Carta anua correspondiente a los años 1637 - 1639. Colegio del Salvador. Buenos Aires. Tomada de apuntes manuscritos del profesor Rogelio Brito.

6 Carta anua correspondiente a los años 1637 - 1639. Colegio del Salvador. Buenos Aires. Tomada de apuntes manuscritos del profesor Rogelio Brito. 
Bracco. "Charrúas, bohanes, pampas y guenoa minuanos en los pueblos de misiones".

y solo avian tomado aquella nueva resolucion, porque les predicava, que el Dios de los Christianos sabe tanto, que nada ignora, y es tan Inmenso, que en todo lugar asiste, mirando quanto sucede; que ellos no querian Dios que viesse tanto, y en sus bosques obravan mas sin registro. Propuseles el zeloso Ministro que igualmente estava Dios presente en el rincon mas retirado de los Infieles, cuyas maldades esta mirando para castigarlas, como Juez de vivos, y muertos, y que las penas les alcançarian mayores á ellos, que aviendo conocido á su Criador, le bolvian tan ingratos las espaldas, por seguir al Demonio, que solo queria llevarlos al Infierno, por una vida tan miserable. \&c. Estas, y otras razones de suma eficacia, no pudieron descantillar aquellos torpes entendimientos de aprehension tan bruta, tras la qual se fue su voluntad, y tan á ciegas, que sin quedar alguno en el Pueblo, dexaron solos á los dos Missioneros, que llorando, con lagrimas del coraçon, la perdida de su rebaño, se retiraron á las otras reduciones, $y$ empressas mas fructuosas" (Jarque 1687, cap. XXV).

Cabe suponer que los charrúas "infieles" generaban importantes problemas para la consolidación de Yapeyú. Al parecer hubo tendencia a impedir o reducir los contactos debido a lo cual los intercambios disminuyeron o cesaron. Por ejemplo, un indígena procedente de las reducciones del Uruguay declaró en Buenos Aires en la década de mil seiscientos treinta "que antiguamente hubieron algunos caballos, pero están ya tan viejos que no son de provecho, que los dichos caballos hubieron de los charrúas con quien contrataban". ${ }^{8}$ Además, cabe señalar que hubo relaciones hostiles desde los albores del establecimiento misional. Así, cuando los indígenas misioneros de la provincia jesuítica del Uruguay comenzaban a emplear el río de ese nombre para comunicarse con Buenos Aires temían a los "yaros [que] antiguamente han ido a su pueblo a hacerles guerra, y que cuando vienen a esta Ciudad, por pasar por la tierra de los yaros vienen con cuidado y prevenidos de flechas y dardos de palo tostado que es las armas que usan". ${ }^{9}$

Esa temprana hostilidad está reflejada elocuentemente ya en la década de 1630. Entonces, unos ochenta indios de Yapeyú habían: "ido a rodear sus vacas desparramadas por aquellos vastos campos, cuando de improviso fueron asaltados por una multitud de yaros". ${ }^{10}$

\footnotetext{
7 Aunque no es posible hacerlo con todos los términos de esas características debido a que el lenguaje no es neutral, se emplearon comillas para señalar palabras con fuerte connotación etnocéntrica como "infiel" o "apóstata".

8 A.G.I., Charcas 28. Información hecha en Buenos aires a petición del gobernador Pedro Esteban Dávila acerca de los indios uruguay, tapes y viaza. Declaración de Pedro Tabacanbú, Buenos Aires, $1^{\circ}$. de abril de 1634.

9 A.G.I., Charcas 28. Información hecha en Buenos Aires a petición del gobernador Pedro Esteban Dávila acerca de los indios uruguay, tapes y viaza. Declaración de Nicolás Ninguirú, Buenos Aires, $1^{\circ}$. de abril de 1634 .

${ }^{10}$ Carta anua correspondiente a los años 1635 - 1637, del provincial Diego de Boroa. Tucumán, 13 de
} 
Ambos bandos se apropiaban de las mujeres y niños del enemigo. Con obvias consecuencias hacia la demografía de los pueblos, a mediados de la década de 1640, "en el momento en que los charrúas pensaban haberse asegurado la victoria sobre el pueblo de Yapeyú (...) los atacaron por el costado los indios topenses, les obligan a huir, y les matan mucha gente, llevándose prisioneros a las mujeres y a los niños". ${ }^{11}$ Tal remite, para emplear términos actuales, a un hecho central en las relaciones entre unos y otros: la lucha por el potencial reproductivo. En el contexto de esa lucha, durante más de una centuria una gran cantidad de mujeres y niños charrúas pasaron a vivir en los pueblos de misiones. Por ejemplo en un sólo episodio del año 1662, 250 charrúas tuvieron ese destino. ${ }^{12}$

Por otra parte cabe destacar que los charrúas buscaron reiteradas veces el amparo de las reducciones, especialmente el de Yapeyú. Hacia mediados del siglo XVIII, probablemente previendo una campaña militar que se preparaba contra ellos, consta que 145 charrúas se ampararon en ese pueblo. ${ }^{13} \mathrm{Y}$ en la década siguiente se afirmaba que "de los charrúas, que no tienen puesto fijo, y vagan por la parte del sur, se convierten y agregan bastantes al pueblo de Yapeyú, bien que dan más que hacer, por su inconstancia en mantenerlos en pueblo, ya convertidos, que convertirlos". ${ }^{14}$

\section{Guenoa minuanos}

Durante dilatado lapso muchos guenoa minuanos se avinieron a vivir en los pueblos de misiones orientales del Uruguay, especialmente en San Borja. ${ }^{15}$ También fueron relevantes en Santo Tomé. Sin perjuicio de antecedentes comparativamente poco documentados, en el decenio de 1670 existía fuerte interacción. Afirmó un jesuita que en Santo Tomé: “el año de mil y seiscientos y setenta y seis, los guanoas solían traer al pueblo de la Cruz y del Yapeyú, (...) vacas blancas y overas, por yerba y tabaco". ${ }^{16}$ Por entonces esos indígenas habían pedido padres a la Compañía de Jesús para reducirse, aunque por falta de religiosos no se atendió la solicitud. ${ }^{17} \mathrm{~A}$ partir de la década siguiente se produjo documentación abundante y de primera mano que ha llegado hasta nosotros. Entre tales fuentes es fundamental la carta del padre Pedro García fechada en el año

agosto de 1637. En Documentos para la Historia Argentina T. XX. 1929, p. 699.

${ }^{11}$ Carta anua de 1644. Colegio del Salvador. Buenos Aires. Tomado de anotaciones manuscritas del profesor Rogelio Brito.

${ }^{12}$ Carta anua, años 1659 - 1662. Colegio del Salvador. Buenos Aires Tomado de anotaciones manuscritas del profesor Rogelio Brito.

13 A.G.N.A. IX-7-9-4. Auto del gobernador Andonaegui. Buenos Aires, 5 de noviembre de 1750.

${ }^{14}$ A.G.I., Charcas 506. Informe del padre superior de Misiones Guaraníes, Esteban Fina. Candelaria, 3 de febrero de 1764 .

${ }^{15} \mathrm{Al}$ parecer los guenoa minuanos tuvieron reducción propia que luego pasó a ser un barrio de San Borja. Testimonio del padre Miguel Jiménez. Santísima Trinidad, 9 de julio de 1728. A.G.N.A. IX - $17-3-4$. (Misiones -1713 - 1796 - Yapeyú).

16 A.G.N.A. IX - 7 - 9-1. Billete escrito por el Padre Leandro Salinas. 20 de mayo de 1715. En información sobre el derecho que tienen los indios guaraníes a las vaquerías del mar. Julio de 1716 .

17 Archivo General de Indias. Charcas 150. (En adelante A.G.I.) El gobernador de Paraguay, Felipe R. Corvalan al Rey. Asunción, 31 de marzo de 1678. 
Bracco. "Charrúas, bohanes, pampas y guenoa minuanos en los pueblos de misiones".

1683. El referido padre había pasado a la "provincia del Paraguay" en $1658^{18}$ y hablaba la lengua de los guenoa-minuano, sin que haya datos de cómo y cuándo la había aprendido. Con anterioridad a su entrada a los "bárbaros guanoás" entre 17 de setiembre y 23 de octubre de 1683 había estado dos veces en tierras de esos "infieles". De su carta es posible conocer diversos aspectos de la intensa interacción entre los guenoaminuanos y los más australes de los pueblos de misiones del Uruguay. El padre García, el propio día de su salida de Santo Tomé se encontró con un grupo de esos "infieles" que llegaban a vender vacas "como lo suelen hacer". Ya entonces había en pueblos de misiones, guenoa minuanos reducidos. Tal quedó evidenciado porque García, una vez entre los "infieles", pidió al cacique principal que le "diese una hermana, con su marido, y tres o cuatro hijos, que deseaban venir, porque ya tenían aquí otras dos hijas, que habían venido antes". Al mismo tiempo se había empezado a producir un proceso de ida y vuelta que impactó tanto en el espacio de fronteras como en los pueblos de misiones. La carta de García evidencia la existencia de "apóstatas" que tras bautizarse y quizás después de una dilatada permanencia abandonaron la vida en reducción y regresaron a la "infidelidad”. Así, de los “infieles" que él intentó persuadir "se hubieran convertido muchísimos más, si el Demonio no hubiera sembrado cizaña, por medio de un Christiano Apóstata, o mal convertido (...) y fue menester la virtud de Dios, para que no retrocediesen todos". No es posible determinar en qué proporción esos "apóstatas"19 eran guenoa minuanos que regresaban a la "infidelidad" o indígenas de otras naciones que se incorporaban a ellos. ${ }^{20}$

El padre García señaló una problemática cuya entidad desconocemos, relacionada con la poligamia y la asunción de un proceso que debía conducir al repudio de todas (para emplear la expresión occidental) las esposas menos una. Entre quienes siguieron al padre García estuvo un individuo "con toda su familia entre la que figuraban "tres mujeres suyas", sin que se conozca que sucedió con ellas. García también destacó que los guenoa minuanos solicitaban la protección de los pueblos de misiones para sus mujeres y niños mientras iban a la guerra contra otros "infieles". Tal solicitud fue

${ }^{18}$ La carta del padre García está inserta en Jarque 1687, cap. XXIII. Una trascripción reciente puede encontrarse Bracco. 2004.

${ }^{19}$ Pocos años más tarde un jesuita había ido a la "espía” de Maldonado en observación de los movimientos portugueses y relató la relevante actuación de un "apóstata" defendiendo a los suyos. El religioso aguardaba a los guenoa minuanos "con mira de recoger unas pocas de vacas para mi vuelta". El sábado santo recibió a tres de ellos que venían a buscarle y darle parte de cómo el "jueves santo al rayar el alba los habían cercado quince bocas de fuego". Estaban los indígenas todos juntos "con intento de reunirse a mi". Escucharon dos tiros, y creyeron que era el padre, se asomaron a "sus esteras" y se vieron cercados por los portugueses. Estos, en la primera descarga "les mataron a los dos caciques más principales que tenían con otros dos mozos y a otro valentón de ellos, Bernabé el Apóstata, atravesado con un balazo por el muslo, [y les hirieron a otros muchos] Y que ellos visto esto se arrojaron de sus esteras con coraje y valor a la venganza donde de improviso el Bernabé arriba dicho con un bolazo que le acertó en la cabeza al Capitán de los agresores lo tendió de muerte y a los demás haciéndoles volver las espaldas los pusieron en huída, de suerte que en espacio de tres cuadras a todos los quince los mataron" A. G.I., Charcas, 261. Carta del padre Pedro de Sascamburu al padre Simón de León. La Cruz, 25 de mayo de 1688.

${ }^{20}$ Carta del padre García. En Jarque 1687, cap. XXIII. 
recurrente durante dilatado lapso y, por supuesto, el refugio ocasional debe haberse tornado permanente en numerosas ocasiones. ${ }^{21}$

Sin perjuicio de la atracción que podían ejercer las ventajas materiales que los pueblos de misiones ofrecían, individuos en número difícil de cuantificar optaron por vivir allí atraídos por el cristianismo y/o la prédica del padre García. Tal fue el caso de un sobrino del cacique principal quien "no sabia, como los que me habían oído [a García] otras dos veces que yo había estado en sus tierras, no trataban de cosas tan importantes, ni se hablaban en orden a mudar de vida: y que él con aquella sola vez, que me oía, ya no podía sufrir mas". La afirmación antecedente adquiere verosimilitud porque García expresó muchas dudas referidas a la sinceridad de otros guenoa minuanos de quienes afirmaba "que ellos mas apetecían la yerba, y tabaco, que mis platicas. Así lo mostró claro el dicho Cacique; porque solo acudía al fin de las Doctrinas, para entrar á la parte del regalo, que les daba".22

García regresó a Santo Tomé acompañado por 32 "infieles” que debían, a su vez, generar un efecto "llamada". Así lo evidencia un individuo que fue "con la licencia deseada de su tío, que le dijo, le seguiría después; pero que en viéndose ya en la reducción, le avisase como se hallaba con la vida cristiana". En el mismo sentido el diecisiete de noviembre llegaron a Santo Tomé: “doce infieles, con vacas para vender a esta Pueblo, entre ellos venia un hijo del cacique fervoroso, que yo traje, y venía con intento de inquirir, que vida era la de los Christianos, que comodidades, \&c. y volver a informar a otros, que lo deseaban saber". Cabe destacar que los guenoa minuanos emprendían camino de las reducciones con su familia y propiedades, lo que hasta cierto punto debía dificultarles regresar a la "infidelidad". Uno de ellos para poder partir sin oposición de los suyos, "se levantó á media noche, dejando cantidad de bacas, y caballos, que tenia, y se partió a aquella hora". ${ }^{23}$

Al parecer -la redacción del texto no permite establecerlo con seguridad- en el año 1685 los guenoa-minuanos eran tantos que se fundó con ellos una reducción, quizás Jesús María de los guenoas, que durante prolognado lapso estuvo asociada a San Borja (Jarque 1687, cap. XXV).

En las décadas siguientes fueron muy numerosas las ocasiones en que grupos de guenoa minuanos se avinieron a la vida en reducción, especialmente en San Borja. La documentación evidencia que mantuvieron permanente contacto con sus parientes que permanecían en la "infidelidad". En ese sentido es significativo un plan esbozado en el contexto de la gran guerra de los años 1701 y 1702 que enfrentó a la sociedad jesuítico misionera y sus aliados guenoa minuanos con una coalición "infiel". Para llevar a cabo con éxito desde la coalición "infiel" se habría decidido:

"acabar primero con los Guenoas por q estos no den aviso a sus parientes los convertidos y por este camino llegue a noticia de los padres, apoderándose de esta suerte primero

\footnotetext{
${ }^{21}$ Carta del padre García. En Jarque 1687, cap. XXIII.

${ }^{22}$ Carta del padre García. En Jarque 1687, cap. XXIII.

${ }^{23}$ Carta del padre García. En Jarque 1687, cap. XXIII.
} 
Bracco. "Charrúas, bohanes, pampas y guenoa minuanos en los pueblos de misiones".

de las Vaquerías, y dando después sobre los dichos pueblos del Yapeyú y la Cruz, que están más desamparados y estos destruidos, pasar a San Borja y Santo Thome antes que los puedan socorrer los Pueblos de arriba". ${ }^{24}$

Durante unos años, al parecer como consecuencia de la expulsión de los portugueses de Colonia del Sacramento en 1705 y tal vez por la gran arreada de ganado de ese año (González, 1705) hubo modificaciones en el sistema de alianzas que había sido tradicional. Así, durante poco menos que una década la relación entre guenoa minuanos y sociedad jesuítico misionera tendió a la hostilidad. En ese contexto un jesuita acudió:

"para ver que reparo se podía poner en tanto daño. Y me quise valer de los guenoas cristianos de Jesús María, rogándoles que hablasen a sus parientes, pues venían alli cada dia, y los exhortasen a la paz, y que entregasen a los cautivos recién llevados, ofreciéndoles por ellos rescate, y que se les perdonarían todos los insultos pasados. Pero estaban tan lejos de eso, que antes defendieron con gran resolución a sus parientes, alegando con demasiada energía que se les hacia notable agravio, levantándoles falsos testimonios, como otras veces, porque no ellos sino los mbohas [bohanes] y yaros eran los que cometian semejantes maldades. [Tras considerar] "inexcusable hacerles guerra, (...) era medio totalmente necesario retirar de San Borja a todos los de Jesús María de los guenoas, de quienes había mucho que reclamar, así de que algunos de ellos, menos fundados en la fe, se fueron a los infieles, como de que aún los más seguros de ellos podrían servir de espías dobles, que avisasen a sus parciales de todos nuestros designios. Así se ejecutó con no poca dificultad $y$ sentimiento de ellos, pero no sin traza y ardid de nuestra parte, dando con todo su pueblecillo, de cerca de cien familias, cuando ellos menos lo pensaron, en el Paraná, donde los agregaron a la doctrina de Nuestra Señora de Loreto". ${ }^{25}$

Hacia 1710 o 1713 las relaciones entre guenoa minuanos y sociedad jesuítico misionero se recompusieron (Lozano, 1874, I, 466) sin que el autor de esta contribución conozca si los desnaturalizados a Nuestra Señora de Loreto regresaron a San Borja. No

${ }^{24}$ A.G.N.A. IX-41-1-3. exp. 1, fs. 148 - 149. Papel presentado por el provincial de la Compañía de Jesús, padre Ignacio de Trías al gobernador de Buenos Aires, remitido por el padre superior de Misiones. Declaración adjunta.

25 "Estado general de las doctrinas del Uruguay del año 1707 en carta escrita al padre provincial de la Compañía de Jesús por el padre Salvador de Rojas, fecha en el pueblo de San Borja a 20 de diciembre de 1708". Copiado por Rogelio Brito de una copia de Antonio Monzón, que debe serlo de las P. Hernández, del Colegio del Salvador (Bs. As.) de los originales de la colección De Angelis. La copia dice “Angelis 939”. 
obstante abundante documentación muestra guenoa minuanos cristianos que residían en ese pueblo y continuaban interactuando con sus parientes "infieles". Así por ejemplo, de ese pueblo salió el padre Jiménez que promovió el acuerdo que puso fin a la guerra contra la recién fundada Montevideo. El mencionado jesuita iba a acompañado de guenoa minuanos cristianos que desempeñaron un rol relevante. Asimismo cabe destacar que, concluida su misión, regresó con apóstatas a los que había podido convencer. ${ }^{26}$

Parte considerable de los guenoa minuanos que consiguieron sobrevivir a la campaña de exterminio llevada contra ellos desde Montevideo en 1751 lo hicieron merced al amparo de los pueblos de misiones (Bracco, 2013). Poco más tarde y sin perjuicio de que el grueso de los guenoa minuanos católicos se trasladó a Santo Tomé en el contexto de la denominada guerra guaranítica, (Martínez Martín, 1998) esos indígenas parecen haber desempeñado roles de dirección en el ejército misionero. ${ }^{27}$ Entre otros, Gomes Freire de Andrade señaló que a las tropas misioneras: "se les unieron los minuanes, cierta nación más belicosa y más fiel que los tapes, y viniendo a mi presencia con los caciques de estos y de los minuanes (...) esta nación, que cierto es la más guerrera que ellos podían llamar a su socorro". ${ }^{28}$ No obstante, las afirmaciones parecen referidas a los “infieles" de esa nación. Quizás por ello, en la década de 1760, varias parcialidades de guenoa minuanos procedentes de las misiones buscaron autorización para vivir en jurisdicción de Montevideo al "ver el desabrigo que había experimentado tenían sus hijos en los pueblos de las misiones, por no haber auxiliado en la guerra de los indios de los padres [jesuitas] por verse en un total desamparo con sus hijos en aquellas partes, se había venido a buscar amparo y a someterse a este gobierno. ${ }^{29}$

\section{Los guenoa minuanos misioneros y la propiedad de la tierra}

Una evidencia relevante de la participación de los guenoa minuanos en el proyecto jesuítico misionero puede encontrarse en los títulos de tierras para los cristianos de esa nación y para los que en adelante se avinieran a dejar la "infidelidad".

En los "títulos de las tierras de Jesús María" expedido por el superior de Misiones en agosto de 1697 consta que el: “capitán y los demás del cabildo de Jesús María de nación guenoa recién convertidos que asisten en el pueblo de san Borja", previniendo que en adelante se conviertan todos los de su nación, teniendo ahora sus ganados en tierras de San Borja, pedían tierras propias "en que tener ganado competente, así mayor como menor, para conservación y sustento". Por lo mismo solicitaban que se les señalara "estancia suficiente". En respuesta el referido superior indicó: "les doy

${ }^{26}$ Biblioteca Nacional - Madrid. Ms. № 12.977 34. Carta del Padre Miguel Ximénez, de 10 de agosto de 1731, transcrita por el padre Pedro Lozano al padre Procurador general Sebastián de San Martín, Córdoba de Tucumán, 30 de enero de 1732. La carta del padre Jiménez está entre p. 26 y 28 del original.

${ }^{27} \mathrm{La}$ asistencia militar que los guenoa minuanos "infieles" prestaron a la sociedad jesuítico misionera precisaría un estudio específico. Diversa documentación ha sido publicada en López y Bracco 2010.

${ }^{28}$ En Castro e Almeida 1913 - 1921: VIII, doc. 18218. Oficio de Gomes Freire de Andrade a Sebastiäo José de Carvalho. Rio Grande, 20 de febrero de 1755.

${ }^{29}$ Actas del Cabildo de Montevideo. En Revista del Archivo General Administrativo. Op. Cit., Tomo III, pp. $288-293$. 
y señalo las tierras que están en la otra banda del Ybicuytí, que se contienen entre dicho río Ybicuytí, que le servirá de un costado, y por el otro un arroyo que llaman Ybirapitá guaçú, que es lindero de las tierras de Yapeyú y va corriendo la dicha tierra hasta las cabezadas, inclusive, del Tapitaguá que llaman los indios (...) hasta que algún gobernador o ministro de Su Majestad les dé título en su nombre". ${ }^{30}$

Reafirmando los derechos que los guenoa minuanos tenían sobre sus tierras, a fin de la década de 1720 el padre Miguel Jiménez declaró les pertenecían desde muchos años atrás, al parecer desde antes que Jesús María de los Guenoas se incorporara a San Borja. $^{31}$

El jesuita mencionado mantuvo en reserva esa información para luego, no estando ya más a cargo de San Borja, testimonió por orden del padre provincial Laurencio Rillo "para que junto con los títulos y otros papeles que tienen, se presentaran los borjistas y guanoas, con los apostolinos ante los jueces que para esta causa eligieren". ${ }^{22}$

Ante el padre Herrán, como árbitro, se dilucidó la cuestión, en la que los representantes de San Nicolás reconocieron que los de Jesús María "tenían mejor y anterior derecho" cediendo en nombre de su cabildo las tierras en disputa. ${ }^{33}$

\section{Cautivas en la sociedad jesuítico misionera}

La documentación evidencia que muy numerosos "infieles" aceptaron el cristianismo y se integraron voluntariamente a la vida en los pueblos de misiones. Sin perjuicio de ello, muchos, casi exclusivamente mujeres y niños, fueron forzados a la vida en reducción. En el espacio de fronteras, y sin perjuicio de numerosos ejemplos anteriores en el tiempo, en los años 1701 y 1702 más de 500 mujeres y niños cautivas fueron enviadas a la fuerza a los pueblos de misiones tutelados por los jesuitas. Ello aconteció como consecuencia de la guerra entre una coalición "infiel” y el ejército jesuítico misionero que contaba con la cooperación de los "infieles" guenoa minuanos. En el contexto de esa guerra, el 6 de febrero de 1702 los misioneros sorprendieron a la coalición "infiel” en las márgenes del río Yi. Según los jesuitas:

"siempre estuvieron protervos los enemigos, queriendo primero morir al rigor de nuestras armas que entregarse (...) y por esta causa perecieron casi todos los hombres de pelea, y no pocas mujeres porque estaban con sus arcos y flechas peleando con los mismos varones (...) [Se les ha capturado] mucha chusma

${ }^{30}$ Títulos de las tierras de Jesús María. A.G.N.A. IX - 6-9-7.

${ }^{31}$ El padre Miguel Jiménez. Santísima Trinidad, 9 de julio de 1728. A.G.N.A. IX $-17-3-4$. (Misiones -1713 - 1796 - Yapeyú).

${ }^{32}$ El padre Miguel Jiménez. Santísima Trinidad, 9 de julio de 1728. A.G.N.A. IX $-17-3-4$. (Misiones -1713 - 1796 - Yapeyú).

${ }_{33}$ Títulos de las tierras de Jesús María, expedido por el superior de Misiones, padre Simón de Leon. San Borja, 9 de agosto de 1697. Copia y corrección del padre Jayme Aguilar, sin lugar, 7 de junio de 1735. A.G.N.A. IX $-6-97$ 
de mujeres y niños que pasan de quinientas almas. ${ }^{34}$ Ese medio millar de "piezas" cautivas fue repartido en distintos pueblos de misiones cuidando "de que en ningún tiempo se puedan volver a sus tierras", y encargando especialmente su adoctrinamiento cristiano a los respectivos padres". 35

En 1707 o 1708 mujeres charrúas fueron capturadas y sufrieron la misma suerte que las anteriores. ${ }^{36}$ También en la campaña militar del año 1709 llevada a cabo por un ejército jesuitico misionero (contra los guenoa minuanos, en momentos en que los sistemas tradicionales de alianza habían variado) "al amanecer del día siete [de diciembre de 1708] en las tolderías, que eran seis, con muerte de Yaguareté y otros siete, apresáronse sus mujeres" e hijos. ${ }^{37}$

Cabe suponer que las ocasiones en que se capturaron mujeres y niños fueron muchas más que las documentadas. En el año 1726 la recurrente hostilidad de los charrúas preponderantes entre los ríos Paraná y Uruguay hacia los jesuitas fue atribuida a que estos cautivaban sus mujeres y niños, obligándolos a la vida en reducción. ${ }^{38}$ En una ocasión, los "infieles capturaron al jesuita "Matheo Sánchez y lo desnudaron, sin dejarle en todo el cuerpo más de las botas y el bonete, y poniéndole colgadas del pescuezo mucha porción de bolas, lo largaron sin hacerle otro daño" y se atribuyó el hecho al odio que tenían a los padres por llevarles mujeres e hijos de vecindad de Corrientes. ${ }^{39}$ Y, desde territorio del actual Uruguay, en el contexto de la violenta campaña llevada adelante por la sociedad colonial contra los charrúas en el año 1750 se enviaron "seis piezas de las que se cogieron a los charrúas" a Yapeyú". ${ }^{40}$

Cabe destacar que los pueblos de misiones de la Compañía de Jesús se visualizaban como el sitio más adecuado para que las cautivas perdieran su identidad. Como ya se ha visto, el medio millar enviado como consecuencia de la guerra de 1701 y 1702 debía ser dispersado en diferentes pueblos. Y a mediados del siglo XVIII, en oportunidad en que se iban a enviar dos lanchas al pueblo misionero de Yapeyú a buscar cueros se pidió que llevaran las "infieles" pampas que estaban en Santo Domingo

${ }^{34}$ A.G.N.A. IX-41-1-3. exp. 1, fs. 335 - 336. El padre Mateo Sánchez al gobernador de Buenos Aires. "De este camino y paraje del Tacuarembotí", 28 de febrero de 1702.

${ }^{35}$ A.G.N.A. IX-41-1-3. exp. 1, fs. 339 - 340. El padre Juan Bautista de Zea al gobernador de Buenos Aires. Santo Tomé, 12 de marzo de 1702.

${ }^{36}$ A.G.N.A. VII - Colección Lamas, Legajo 6. "Misiones jesuíticas / Diario de los sucesos y de las operacio / nes de guerra de los dos tercios de / indios de las Misiones conducidos / por los Padres de la Compañía de / Jesús contra los indios infieles del / Uruguay. / Por el padre Jerónimo Herrán. / 1709".

${ }^{37}$ A.G.N.A. VII - Colección Lamas, Legajo 6. "Misiones jesuíticas / Diario de los sucesos y de las operacio / nes de guerra de los dos tercios de / indios de las Misiones conducidos / por los Padres de la Compañía de / Jesús contra los indios infieles del / Uruguay. / Por el padre Jerónimo Herrán. / 1709".

${ }^{38}$ A.G.I., Buenos Aires, 235. Probanza dada en Asunción por parte del capitán Juan de Mena Ortiz y Velasco. Año 1728. Declaración de Juan de Gamarra.

${ }^{39}$ A.G.I., Buenos Aires, 235. Probanza dada en Asunción por parte del capitán Juan de Mena Ortiz y Velasco. Año 1728. Declaración de Gregorio Cipriano de Ruti.

${ }^{40}$ A.G.N.A. IX-4-3-1. Carta de José de San Román al gobernador de Buenos Aires. Santo Domingo, 16 de enero de 1750. 
Bracco. "Charrúas, bohanes, pampas y guenoa minuanos en los pueblos de misiones".

Soriano. ${ }^{41}$ Se afirmaba que esas mujeres "nunca aquí se han de reducir a la ley de Dios por estar juntas, y en las Misiones sí, porque allí las apartarán en diferentes pueblos" ${ }^{42}$

\section{Tras la expulsión de los jesuitas}

Apenas producida la expulsión, religiosos de otras órdenes continuaron ofreciendo refugio en los pueblos de misiones. ${ }^{43}$ En el contexto de violencia que se vivía en el espacio de fronteras se mantuvo el proceso por el cual indígenas -en ocasiones varios cientos- se establecieron transitoria o permanentemente en los pueblos. ${ }^{44}$ Sin perjuicio de los que lo hicieron voluntariamente muchos continuaron siendo compelidos a vivir en los pueblos. Por ejemplo, a fin del año 1799 un oficial dependiente del teniente gobernador de Yapeyú había tenido un encuentro con esos "infieles" y pocas semanas más tarde atacó "una toldería de minuanes aprisionando treinta y dos familias. ${ }^{45} \mathrm{Ya}$ en el siglo XIX y a medida que se acentuó el proceso de decadencia continuaron interactuando, retornando al territorio de sus ancestros y participando en los procesos que condujeron a la formación de los estados de la región (Padrón, 1996; Barreto y Curbelo, 2008; Rodríguez y González, 2010; Cabrera Pérez, 2011; Neumann, 2014).

Expresado apenas a modo de conjetura (una sola fuente hasta cierto punto extemporánea no autoriza a otra cosa) útil para visualizar la entidad del fenómeno quizás el dirigente artiguista conocido como Andresito ${ }^{46}$ y sus jefes de su división eran de los guenoa minuanos que ellos mismos -o más posiblemente sus antepasados- ${ }^{47}$

${ }^{41}$ Al parecer todas esas mujeres eran de la parcialidad del cacique Calelián quien fue deportado a España con doce de sus principales guerreros y, según la documentación, tuvo un final heroico. A.G.N.A. IX-233-4. Zabala al gobernador de Buenos Aires. Víboras, 15 de noviembre de 1750.

${ }^{42}$ San Román al gobernador. Santo Domingo Soriano, 6 de julio de 1746. A.G.N.A. IX - $4-3-1$.

${ }^{43}$ Fray Marcos Ortíz, en funciones en Yapeyú suplantando a los recién expulsados jesuitas se refirió a sus gestiones para lograr la incorporación de bohanes a ese pueblo. En agosto del año 1768 tras enviar "rastrear" "infieles metidos en esos escondrijos de Santa Tecla y Río Negro consiguió atraer a cuatro caciques -se deduce de las cartas posteriores que se citan a continuación- bohanes. Esos caciques se fueron "muy gustosos con algunos cortos regalos que se les han hecho", prometiendo "arrastrar para este pueblo a todas sus familias, como también a los demás caciques con las familias de su comando". Los bohanes pidieron que se les diera para reducirse "la capilla de San Miguel. Fray Marcos no lo creía conveniente "por estar a la de su nativo terreno". Fray Marcos Ortíz a excelentísimo señor [Bucareli]. Yapeyú, 27 de agosto de 1768. En Colección de documentos relativos a la expulsión de los jesuitas 1872 , p. 234 y ss. Carta $1^{\text {a }}$. Un estudio específico en: Levinton 2003.

${ }^{44}$ En 1794 Francisco Rodrigo, teniente de gobernador de Yapeyú, comunicaba al virrey que 650 charrúas y minuanos habían ido a protegerse en Yapeyú, La Cruz y San Borja, con “deseos de reducirse a vida civil, y muchos de ellos demandando por cristianarse...". A.G.N.A., Tribunales, legajo 66, expediente 38. Oficio del teniente de gobernador de Yapeyú, Francisco Rodrigo, al virrey Arredondo. Yapeyú, 17 de abril de 1794.

45 A.G.N. Colección Pivel Devoto Tomo I, Caja 3, Carpeta 10. Parte de Isfrán a Francisco Bermúdez. Puntas del Cuareim, 9 de febrero de 1800. Copia fechada en Yapeyú el 17 de febrero de 1800.

46 “Dos pueblos misioneros, Santo Tomé y San Borja [los dos con más intensa presencia guenoa minuana] se disputan el honor de haber sido la cuna de Andresito" (Machón, 2005: 123).

${ }^{47}$ De los padrones de San Borja -únicos en que Machón $(2005,123)$ detecto el apellido Guacurarí- se conservan el de 1735 y el de 1772. En el primero "figura un Matías Guacurarí, de aproximadamente 46 años, recién convertido, casado con María Ibayú, con dos hijos Nazario de 17 años y Pascual de 20. En el 
se habían establecido en San Borja. ${ }^{48}$ Más allá de que esa conjetura se demuestre o se refute, parece un hecho que charrúas, guenoa minuanos y pampas, de grado o por fuerza, fueron parte relevante de la población de las reducciones. Por lo mismo, para no excluirlos y para aquilatar su participación ulterior en el espacio de frontera sobre el que se edificó la República Oriental del Uruguay es necesario considerar que esa población excedía lo "guaraní misionero" para ser "indígena misionera".

\section{Referencias Bibliográficas}

Barreto, I. y Curbelo, C. 2008. "Presencia indígena misionera en el Uruguay: movilidad, estructura demográfica y conformación familiar al Norte del Río Negro en el primer tercio del siglo XIX”. En: XII Jornadas Internacionales Misiones Jesuiticas. Interacciones y sentidos de la conversión. CD ROM. Buenos Aires.

Bracco, D. 2004. Charrúas, Guenoas y Guaranies.: interacción y destrucción. Montevideo. Linardi \& Risso.

Cabrera Pérez, L. 2011. "La incorporación del indígena de la Banda Oriental a la sociedad colonial / nacional urbana". En: Revista TEFROS. Vol. 9.

Cartas edificantes y curiosas escritas de las missiones estrangeras y de levante / por Algunos Missioneros de la Compañía de Jesús, Traducidas del Idioma Frances por el Padre Diego Davin de la Misma Compañía. 1753. Madrid. En la Imprenta de la Vda. de Manuel Fernández y del Supremo Consejo de la Inquisición. 8 Tomos. T.VII.

Castro e Almeida, E. 1913-1921. Inventario dos documentos relativos ao Brasil existentes no Archivo de Marinha e Ultramar de Lisboa. Organizados para a Biblioteca Nacional do Río de Janeiro. 8 Vol. Río de Janeiro.

Colección de documentos relativos a la expulsión de los jesuitas de la República Argentina y del Paraguay en el reinado de Carlos III. 1872. Introducción y notas por Francisco Javier Brabo. Madrid. Establecimiento Tipográfico de San Pablo, p. 234 y ss. Carta $1^{\text {a }}$.

Documentos para la Historia Argentina. 1929. T. XX. Iglesia. Cartas Anuas de la Provincia del Paraguay, Chile y Tucumán de la Compañía de Jesús; con advertencia de Emilio Ravignani e introducción del P. Carlos Leonhardt. Talleres, Casa Jacobo Peuser. Buenos Aires.

de 1772, en el mismo cacicazgo, encontramos dos huérfanos, Martín de 12 años, y Tomás de 14, ambos con el apellido Guacurarí, siendo probable que algunos de estos haya sido su padre (Machón, 2005; 125; citando A.G.N.A IX - 18 -2 4 y IX -18 - 8 - 5). Cabe señalar que la condición de recién convertido que se le adjudica a Marías Guacurarí en 1735 evidencia que venía de la "infidelidad".

${ }^{48}$ En un texto en que manifestó igual menosprecio por todos los indígenas y por lo tanto no parece que atribuirle esa condición reforzara sus argumentos en el sentido de denigrarlo, Sarmiento afirmó acerca de Artigas: "Sus soldados son de la misma catadura; son los charrúas, los guaraníes, los minuanos. Andresito es indio minuano". Asimismo según Sarmiento otros comandantes artiguistas habrían sido también guenoa minuanos ya que "Los jefes de esta división eran indios minuanos. El indio Ticurey, el indio Lorenzo Artigas, por adopción como Andresito, el indio Matías Abacú, el indio Juan de Dios, etc.”. (Sarmiento, 1883:162) 
González, S. [1705] 1968. "Diario del viaje que hacen a la Vaquería del Mar, el padre Juan María Pompeyo, y el hermano Silvestre González, entrambos de la Compañía de Jesús". En: Las Vaquerías del Mar. Introducción, notas y mapas del Ing. Esteban Campal. Editorial Arca. Montevideo; págs. 204-216.

Jarque, F. 1687. Insignes misioneros de la Compañía de Jesús. Pamplona. Juan Micon editor.

Levinton, N. 2003. "La burocracia administrativa contra la obra evangelizadora: una reducción de Charrúas fundada por fray Marcos Ortiz", en Primeras Jornadas de Historia de la Orden Dominicana en la Argentina. San Miguel de Tucumán. Universidad del Norte Santo Tomás de Aquino.

López Mazz, J. M. y Bracco, D. 2010. Minuanos: apuntes y notas para la historia y la arqueología del territorio guenoa-minuan. Montevideo. Linardi \& Risso.

Lozano, P. 1874. Historia de la conquista del Paraguay, Río de la Plata y Tucumán. Buenos Aires. Publicada y anotada por Andrés Lamas.

Martínez Martín, C. 1998. "Datos estadísticos de población sobre las misiones del Paraguay, durante la demarcación del Tratado de Límites de 1750”. En: Revista Complutense de Historia de América. 24: 249-261.

Neumann, E. 2014. "Um só nâo escapa de pegar em armas": as populaçôes indígenas na guerra dos farrapos (1835-1845)". En: Revista Historia, São Paulo, No 171, pp. 83-109, jul.-dez. http://dx.doi.org/10.11606/issn.2316-9141.rh.2014.89008

Machón, J. F. 2005. José Artigas, gobernador de Misiones. Posadas. Talleres Creativa.

Padrón Fabre, O. 1996. Ocaso de un pueblo indio. Historia del éxodo guaraní misionero al Uruguay. Fin de Siglo. Montevideo.

Revista del Archivo General Administrativo: o colección de documentos para servir al estudio de la historia de la República Oriental del Uruguay. 1885 - 1943 / patrocinada por el gobierno y dirigida por Pedro Mascardó. Archivo General de la Nación (Uruguay). Montevideo. Imprenta El siglo Ilustrado. Montevideo.

Rodríguez, S. y González Rissoto, R. 2010. En búsqueda de los orígenes perdidos: los guaranies en la construcción del ser uruguayo. Planeta. Montevideo.

Sarmiento, D. F. 1883. Conflicto y armonías de las razas en América. S. Ostwald Editor. Imprenta de D. Túñez. Buenos Aires. Tomo I. 